\title{
Endoscopic submucosal dissection for early gastric cancer in elderly patients: a meta-analysis
}

Jin-ping Lin ${ }^{1,2}$, Ya-ping Zhang ${ }^{3,4}$, Meng Xue ${ }^{1,2}$, Shu-jie Chen ${ }^{1,2^{*}}$ and Jian-min $\mathrm{Si}^{1,2^{*}}$

\begin{abstract}
Background: The effectiveness of endoscopic submucosal dissection (ESD) has been increasingly reported. However, studies addressing the safety and application value of ESD in elderly patients with early gastric cancer (EGC) were still lacking. This meta-analysis was intended to evaluate the feasibility and safety of ESD in elderly patients with EGC.
\end{abstract}

Methods: A systematic search was conducted in PubMed, EBSCO, Cochrane Library, EMBASE, and Web of Science. Studies were screened out if data of elderly and non-elderly gastric cancer patients were reported separately. The qualities of included studies were assessed using Newcastle-Ottawa Quality Assessment Scale. The pooled odd ratios (ORs) with $95 \%$ confidence intervals (Cls) were calculated. Statistical analysis was conducted using the Review Manager 5.2 (Cochrane Collaboration, Oxford, UK).

Results: Nine studies (eight in Japan, one in China), including a total of 30,100 lesions, met the inclusion criteria. The "en bloc" and histological complete resection rates of the elderly and non-elderly groups were similar [OR, 0.98, $95 \% \mathrm{Cl}, 0.56$ to $1.71 ; P=0.93$ and $\mathrm{OR}, 0.79,95 \% \mathrm{Cl}, 0.58$ to 1.07; $P=0.13$, respectively]. As for procedure-related complications, similar perforation rates [OR, 1.19, $95 \% \mathrm{Cl}, 0.94$ to $1.51 ; P=0.15]$, and bleeding rates [OR, 1.13, $95 \%$ $\mathrm{Cl}, 0.83$ to 1.56$) ; P=0.43$ ] between the elderly and non-elderly groups were observed. Whereas, the elderly patients had a higher procedure-related pneumonia rate compared with non-elderly ones [OR, $2.18,95 \% \mathrm{Cl}, 1.55$ to 3.08 ; $P<0.01]$.

Conclusions: The ESD procedure appears to be a safe technique in elderly patients with EGC while appropriate approach should be taken to avoid procedure-related pneumonia.

Keywords: Endoscopic submucosal dissection, Early gastric cancer, Elderly patients, Meta-analysis

\section{Background}

Gastric cancer remains one of the major life-threatening problems worldwide, especially in some eastern Asian countries [1, 2]. Various therapeutic options are available currently, including endoscopic treatment, laparoscopic gastrectomy and conventional open surgery. Early gastric cancer (EGC), defined as lesions confining to the gastric mucosa or submucosa [3], usually has a low risk of lymphatic metastasis, thus allowing radical resection of lesions without lymphadenectomy. Endoscopic mucosal resection (EMR) was firstly introduced for intramucosal gastric cancer. However, if the lesions are larger than

\footnotetext{
* Correspondence: chensj77@hotmail.com; jianmin_si@zju.edu.cn 'Department of Gastroenterology, Sir Run Run Shaw Hospital, School of Medicine, Zhejiang University, 3 East Qingchun Road, Hangzhou 310016, Zhejiang, People's Republic of China

Full list of author information is available at the end of the article
}

$20 \mathrm{~mm}$ or have invaded into the submucosa, EMR may lead to piecemeal resection and subsequent recurrence, which has been replaced by endoscopic submucosal dissection (ESD). ESD has been proven to be an effective therapeutic method for EGC. A high "en bloc" resection rate would be achieved if the indications are properly followed [4-6].

Despite the fact that surgical operation is the mainstay in the management of gastric cancer, elderly patients with comorbidities and poor functional capacities might not be able to endure such aggressive surgical trauma. Previous studies reported that the incidence of postoperative complications was quite frequent among elderly patients with EGC [7]. Furthermore, the integrity of the stomach plays a critical role in maintaining a normal condition of elderly patients. Patients after gastrectomy 
are at risk of vitamin B12 deficiency and anemia [8,9]. In the past decade, cases of elderly EGC patients undergoing ESD were strikingly increased. However, studies reporting the treatment of EGC by ESD in elderly patients have been published previously, reliable evidence seems still lacking due to small sample sizes. Thus, we performed this systematic review and meta-analysis to evaluate the feasibility and safety of ESD in elderly patients with EGC by comparing with non-elderly patients.

\section{Methods}

\section{Search strategy and study selection}

A systematic search was conducted in PubMed, EBSCO, Cochrane Library, EMBASE, and Web of Science to identify articles published until May 2015. The following search algorithms "(((elderly[Title/Abstract]) OR old[Title/ Abstract]) OR geriatric[Title/Abstract])) AND ((((early gastric cancer) OR early gastric neoplasm)) AND (((endoscopic submucosal dissection) OR ESD) OR endoscopic resection))" were used. Besides, the reference lists are manually viewed to obtain additional relevant articles. Search was restricted to English and Chinese literature.

The inclusion criteria were as follows: peer-reviewed studies reporting comparison of elderly and non-elderly patients underwent ESD, full texts were available. The exclusion criteria were as follows: studies of which the measured outcomes were not clearly presented or difficult to calculate, duplicate studies, case reports, review articles, editorials, and letters.

\section{Data extraction and quality assessment}

The articles identified by our search strategy were screened by two independent reviewers (JPL and YPZ). Disagreements were resolved through discussion with other two researchers (SJC and JMS). Extracted data including author, study period, geographical region, number of lesions, "en bloc" resection rates (no piecemeal removal of the lesion) and histologically complete resection rates (no neoplastic cells in lesion edges), perforation, procedure-related bleeding, and procedure-related pneumonia. Perforation was diagnosed intraoperatively or by the presence of free air on plain radiograph or CT images after ESD. Procedure-related bleeding was defined as clinical evidence of bleeding after ESD. Procedure-related pneumonia was defined as new or progressive lung consolidation with clinical symptoms after ESD. The Newcastle-Ottawa Quality Assessment Scale (NOS) was used as a quality assessment tool. Scale varies from zero to nine stars: studies with a score equal to or higher than six were considered methodologically sound.

\section{Statistical analysis}

Dichotomous variables were analyzed using the odd ratio (OR) with $95 \%$ confidence intervals (CIs). Statistical heterogeneity was evaluated using methods described by Higgins et al. [10]. $I^{2}$ values between 0 and $25 \%$ suggest low heterogeneity, values above $25 \%$ suggest moderate heterogeneity, and values above $75 \%$ suggest high heterogeneity. Pooled effect was calculated using Mantel-Haenszel test for fixed-effects models (in case of low heterogeneity) or DerSimonian and Laird test for random-effects models (in case of moderate or high heterogeneity) $[11,12]$. The potential publication bias based on the procedure-related complications was assessed by conducting the funnel plots. Data analysis was performed using Review Manager 5.2 (Cochrane Collaboration, Oxford, UK). $P<0.05$ was considered as statistically significant.

\section{Results}

\section{Characteristics of included studies}

Initially, 323 potentially relevant articles were identified to undergo abstract review. Nine full-text studies were screened out for the final analysis [13-21]. The flow chart of the screening strategies was presented in Fig. 1.

This meta-analysis pooled 30,100 lesions, 6713 in elderly patients group and 23,387 in non-elderly patients group. All of these studies were carried out retrospectively with eight in Japan and one in China. No less than six stars according to the NOS were scored for each of them. The definition of elderly patients was no less than 65 years old in one study [19], no less than 80 years old in another study [20] and no less than 75 years old in the rest seven studies [13-18, 21]. General characteristics, measurements of comparability and the quality of studies were summarized in Table 1.

Operative outcomes and procedure-related complications Six studies reported the "en bloc" resection rates $[13,14$, 17-19, 21]. In total, "en bloc" resection was performed in 907 out of 973 lesions in the elderly patients group and 1089 out of 1173 lesions in the non-elderly patients group. The "en bloc" resection rates were comparable between the two groups $[\mathrm{OR}=0.98 ; 95 \% \mathrm{CI} 0.56$ to 1.71; $P=0.93$ ] (Fig. 2a).

Five studies reported the histological complete resection rates $[13,17-19,21]$. Similar with the "en bloc" resection rates, no significant difference was observed between the two groups $[\mathrm{OR}=0.79 ; 95 \% \mathrm{CI} 0.58$ to 1.07; $P=0.13$ ] (Fig. 2b).

Data on the perforation rates were reported in nine studies [13-21]. The perforation rate in the elderly patients group (105/6713) was comparable to that in the non-elderly patients group $(250 / 23,387), \quad[\mathrm{OR}=1.19$; $95 \%$ CI 0.94 to $1.51 ; P=0.15]$, (Fig. 3a). Procedurerelated bleeding rates were examined in nine studies [13-21] and no significant difference was found between the two groups (elderly vs. non-elderly, 224/6713 vs. 


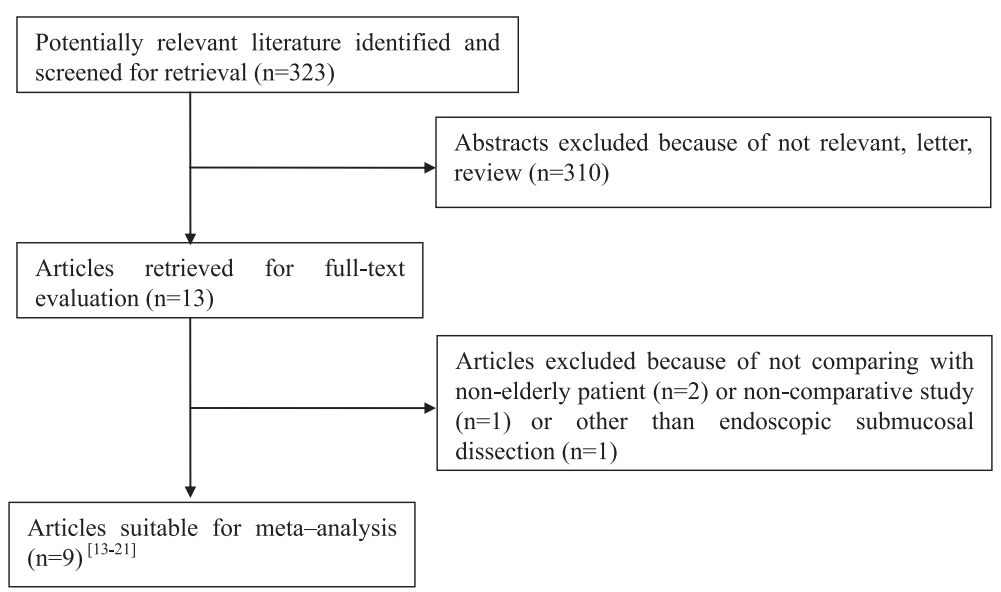

Fig. 1 The PRISMA flowchart of literature review

687/23,387), [OR $=1.13 ; 95 \%$ CI 0.83 to $1.56 ; P=0.43$ ], (Fig. 3b). Five studies reported the procedure-related pneumonia rates $[14,17-20]$. The elderly patients group had a higher risk of procedure-related pneumonia (elderly vs. non-elderly, $56 / 6495$ vs. $89 / 23,839)$, $[\mathrm{OR}=2.18$; $95 \%$ CI 1.55 to $3.08 ; P<0.01$ ] (Fig. 3c). A summary of operative outcomes and procedure-related complications was showed in Table 2.

\section{Publication bias}

The funnel plots based on the procedure-related complications (perforation, procedure-related bleeding and procedure-related pneumonia) were generated (Fig. 4). No evident publication bias was observed. Sensitivity analysis was performed by exclusion of the highest weighted study or the two studies which did not define elderly patients as "no less than 75 years old" $[19,20]$ in each pooled analysis. The results were all consistent with the outcomes mentioned above.

\section{Discussion}

Owing to the advance in medicine and health care, the global population of the elder has been increasing [22]. An accompanying issue is that neoplastic diseases would be more common, including gastric cancer [23, 24]. Endoscopic treatments have gradually gained their popularity and are currently established as the standard treatment for EGC $[25,26]$. ESD is a promising approach of endoscopic treatment, which allows "en bloc" resection for large lesions and recurred less than EMR [27-29]. A meta-analysis pooling ten studies demonstrated the "en bloc" and histological complete resection rates were significantly higher in the ESD compared with EMR [30]. However, ESD is also associated with high frequencies of procedure-related complications, such as perforation, postoperative bleeding, and pneumonia. [29-31]. ESD is expected to be a promising alternative for elderly patients with EGC because of its minimal invasiveness and retainment of integrated stomach when compared with gastrectomy. However, published studies on the application of ESD were not adequately robust to support or refute its feasibility and safety in elderly patients with EGC. Hence, a systematic review pooling the latest evidence was necessary to address this issue.

The long-lasting procedure was one of the drawbacks during ESD. The duration time differed a lot among these studies $[13,14,18,19,21]$. This can be explained with the learning curve of endoscopists and the locations of tumor which might mostly reside in upper and/or middle portion of the stomach. Factors associated with the longer procedure include locations and sizes of tumor and the presence of ulcer and scar [26, 32]. The influence of age on duration time was assumed to be limited based on the same nature of the procedure, although poor conditions of the elderly patients might need more complex operation. Our present study also showed no significant difference between two groups.

The procedure-related complications are not only preferred parameters to evaluate the feasibility and safety of an operation but also significantly affect the length of hospitalization and medical expenses. Perforation is one of the most common drawbacks accompanying ESD. Perforation after ESD occurs at a rate of 1.2 to $8.2 \%$ $[26,33,34]$, even in experienced hands. Our metaanalysis showed that perforation rate was about $2 \sim 4 \%$, irrespective of the patients' age. Intriguingly, less perforation was reported if the lesions were small and locates at the lower or middle portion of stomach [35, 36]. Nowadays, thanks to the development of endoscopic clipping and prompt use of antibiotics, perforation is no longer an obstacle in most cases. 
Table 1 Characteristics of included studies

\begin{tabular}{|c|c|c|c|c|c|c|c|c|c|c|c|c|c|c|}
\hline Study & Period & Country & $\begin{array}{l}\text { Study } \\
\text { design }\end{array}$ & Group & $\begin{array}{l}\text { Sample } \\
\text { size }\end{array}$ & $\begin{array}{l}\text { Mean } \\
\text { age }\end{array}$ & $\begin{array}{l}\text { Gender } \\
(\mathrm{M} / \mathrm{F})\end{array}$ & $\begin{array}{l}\text { Comorbidity } \\
\text { (\%) }\end{array}$ & $\begin{array}{l}\text { Ulcer } \\
\text { findings }\end{array}$ & Location (U/M/L) & $\begin{array}{l}\text { Invasion } \\
\text { depth (S/SM) }\end{array}$ & $\begin{array}{l}\text { Tumor size } \\
(\mathrm{mm})\end{array}$ & $\begin{array}{l}\text { Comparability } \\
\text { of baseline } \\
\text { characteristics }\end{array}$ & $\begin{array}{l}\text { Study quality } \\
\text { score }\end{array}$ \\
\hline \multirow[t]{2}{*}{ Hirasaki [13] } & $\begin{array}{l}2000- \\
2004\end{array}$ & Japan & R & $\mathrm{E}$ & 53 & 78.2 & $34 / 19$ & 57 & NR & NR & $47 / 6$ & 12.2 & abf & 6 \\
\hline & & & & $\mathrm{NE}$ & 91 & 64.7 & $74 / 17$ & 33 & NR & NR & $83 / 8$ & 13 & & \\
\hline \multirow[t]{2}{*}{ Shimura [14] } & $\begin{array}{l}2002- \\
2006\end{array}$ & Japan & R & $\mathrm{E}$ & 45 & NR & $33 / 8$ & 65.9 & NR & $6 / 25 / 14$ & NR & 16 & $a b c$ & 7 \\
\hline & & & & $\mathrm{NE}$ & 80 & NR & $57 / 18$ & 31.3 & NR & $11 / 36 / 33$ & NR & NR & & \\
\hline \multirow[t]{2}{*}{$\begin{array}{l}\text { Kakushima } \\
\text { [15] }\end{array}$} & $\begin{array}{l}2000- \\
2004\end{array}$ & Japan & R & $\mathrm{E}$ & 49 & NR & NR & NR & NR & NR & NR & NR & NR & 6 \\
\hline & & & & $\mathrm{NE}$ & 135 & NR & NR & NR & NR & NR & NR & NR & & \\
\hline \multirow[t]{2}{*}{ Onozato [16] } & $\begin{array}{l}2002- \\
2006\end{array}$ & Japan & R & $E$ & 110 & 79.8 & $50 / 43$ & NR & $14 / 96$ & $18 / 45 / 47$ & $102 / 8$ & 22.8 & bcef & 6 \\
\hline & & & & $\mathrm{NE}$ & 141 & 66 & $106 / 27$ & NR & $24 / 117$ & 25/35/81 & $114 / 27$ & 21.8 & & \\
\hline \multirow[t]{2}{*}{ Isomoto [17] } & $\begin{array}{l}2001- \\
2007\end{array}$ & Japan & R & $E$ & 279 & NR & 173/106 & NR & 3.7 & $44 / 129 / 105$ & $222 / 57$ & 20 & bcf & 6 \\
\hline & & & & $\mathrm{NE}$ & 434 & NR & $343 / 91$ & NR & 13.3 & 73/209/149 & $369 / 65$ & 19 & & \\
\hline \multirow[t]{2}{*}{$\begin{array}{l}\text { Toyokawa } \\
\text { [18] }\end{array}$} & $\begin{array}{l}2003- \\
2009\end{array}$ & Japan & R & $E$ & 229 & 80 & $128 / 72$ & 153 & 11.8 & $54 / 76 / 98$ & $158 / 28$ & 19 & bcdef & 8 \\
\hline & & & & $\mathrm{NE}$ & 357 & 66 & $237 / 77$ & 93.66 & 10.1 & $93 / 141 / 122$ & $245 / 41$ & 18 & & \\
\hline \multirow[t]{2}{*}{ Tokioka [19] } & $\begin{array}{l}2002- \\
2010\end{array}$ & Japan & R & $E$ & 372 & 73.9 & $260 / 112$ & 115.3 & NR & $25 / 109 / 229$ & $367 / 5$ & 15.1 & abcdf & 7 \\
\hline & & & & $\mathrm{NE}$ & 143 & 57.7 & $118 / 25$ & 58.8 & NR & $23 / 45 / 74$ & $138 / 5$ & 14.5 & & \\
\hline \multirow[t]{2}{*}{ Murata [20] } & $\begin{array}{l}2009- \\
2010\end{array}$ & Japan & R & E & 5525 & NR & $3619 / 1906$ & 61.7 & NR & $569 / 2801 / 2155$ & NR & NR & NR & 6 \\
\hline & & & & $\mathrm{NE}$ & 21,860 & NR & $\begin{array}{l}16,657 / \\
5203\end{array}$ & 44.4 & NR & $\begin{array}{l}\text { 1880/12,001/ } \\
7979\end{array}$ & NR & NR & & \\
\hline \multirow[t]{2}{*}{ Zhang [21] } & $\begin{array}{l}2010- \\
2013\end{array}$ & China & R & $\mathrm{E}$ & 51 & 79 & $33 / 13$ & 76.1 & $11 / 51$ & $9 / 17 / 24$ & $40 / 11$ & 19 & abcde & 8 \\
\hline & & & & NE & 136 & 59.4 & 79/46 & 37.6 & 21/136 & $9 / 44 / 83$ & 129/7 & 20 & & \\
\hline
\end{tabular}

$M$ male, $F$ female, $L$ lower third of stomach, $M$ middle third of stomach, $U$ upper third of stomach, $E$ elderly group, $N E$ non-elderly group, $R$ retrospective, $N R$ not report, $a$ gender, $b$ tumor size, $c$ tumor location, $d$ macroscopic types, $e$ ulcer findings, $f$ invasion depth 


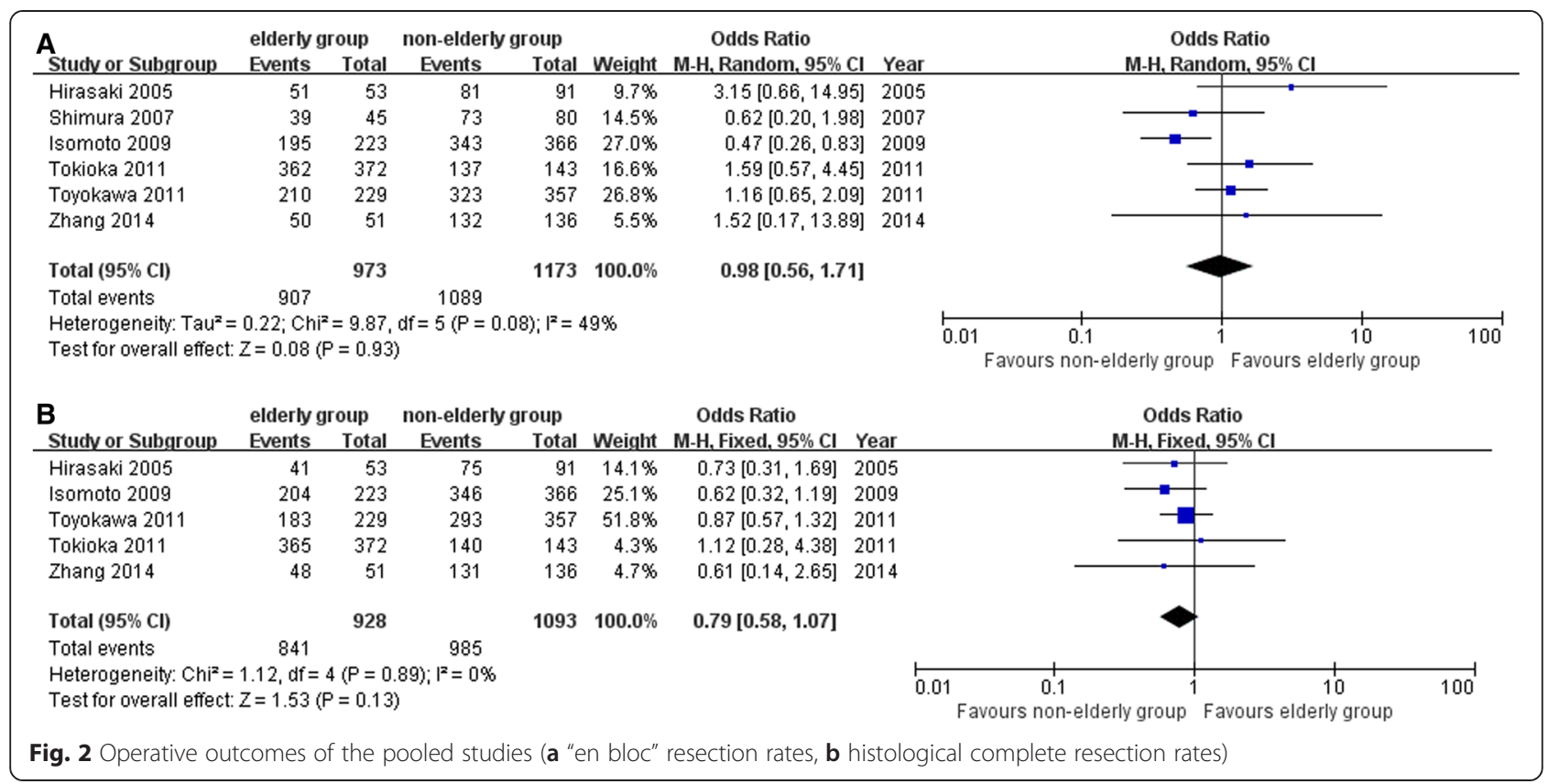

Procedure-related bleeding was another common complication of ESD procedure. It seemed to be associated with factors including the histology, location, and invasion depth of tumor [13, 37, 38]. For the elder, anticoagulant drugs have long been considered as an important relevant factor. However, recent studies reported that continuous administration of anticoagulant drugs was not significantly correlated with procedure-related bleeding [39, 40]. This meta-analysis revealed the bleeding rates between the elderly and non-elderly groups were similar $[\mathrm{OR}=1.13 ; P=0.43]$.

According to this meta-analysis, we inferred pneumonia developed more frequently in the elderly patients. Higher risk of aspiration, poor immunity, and less capability to expectorate after ESD contributes to procedure-related pneumonia in the elderly patients. Adequate suction of saliva during ESD might be helpful to reduce the probability of aspiration [16]. Procedure-related pneumonia was also associated with longer operation time, smoking history, sedation methods, and presence of ulceration [41-43]. Thus, elderly patients combined with risks such as smoking, intractable lesions, are recommend to experienced endoscopists, which may avoid procedure-related pneumonia. Moreover, chest radiography images, WBC count, and C-reactive protein level are recommended in elderly patients who are at high risk of procedure-related pneumonia $[41,44]$. Though without strong evidence, prophylactic use of antibiotics is recommended in these patients.

Two studies reported the follow-up data after the procedure of ESD in elderly patients, and the long-term prognoses were acceptable. Although only few studies reported long-term oncologic outcomes, the "en bloc" resection rate and the histological complete resection rate are also used as indicators of the oncologic adequacy of ESD [25]. The overall 5-year survival rates in the curative resection and non-curative resection were 85 and $63 \%$ in elderly patients [45]. Both of the "en bloc" resection rate and the histological complete resection rate were high in elderly patients, which were in accordance with the previous reports [26, 46]. Compared with Eastern and Western historical studies, these two parameters of elderly patients were not inferior [27, 47, 48]. This meta-analysis also demonstrated that the "en bloc" resection rate and the histological complete resection rate in the elderly patients were comparable with the non-elderly patients.

Several limitations exist in this meta-analysis. Firstly, eligible studies were all non-randomized controlled trials. A symmetric distribution of lesion size and location, varied indications for ESD, inconsistent definition of elderly patients, and procedure-related complications decreased the plausibility of the results. Secondly, in this meta-analysis, some pooled studies included patients with gastric adenoma $[14,18]$. A larger sample size in a meta-analysis may help to obtain a possible treatment effect. The sample size of the rest studies is too small to generalize definitive conclusions of some comparisons. Thus we did not delete these studies, which might be one source of heterogeneity. Thirdly, only studies published in English were pooled in this meta-analysis which may also result in bias. In addition, all nine studies included in this meta-analysis were from East Asia, which may limit its clinical application in Western countries. 


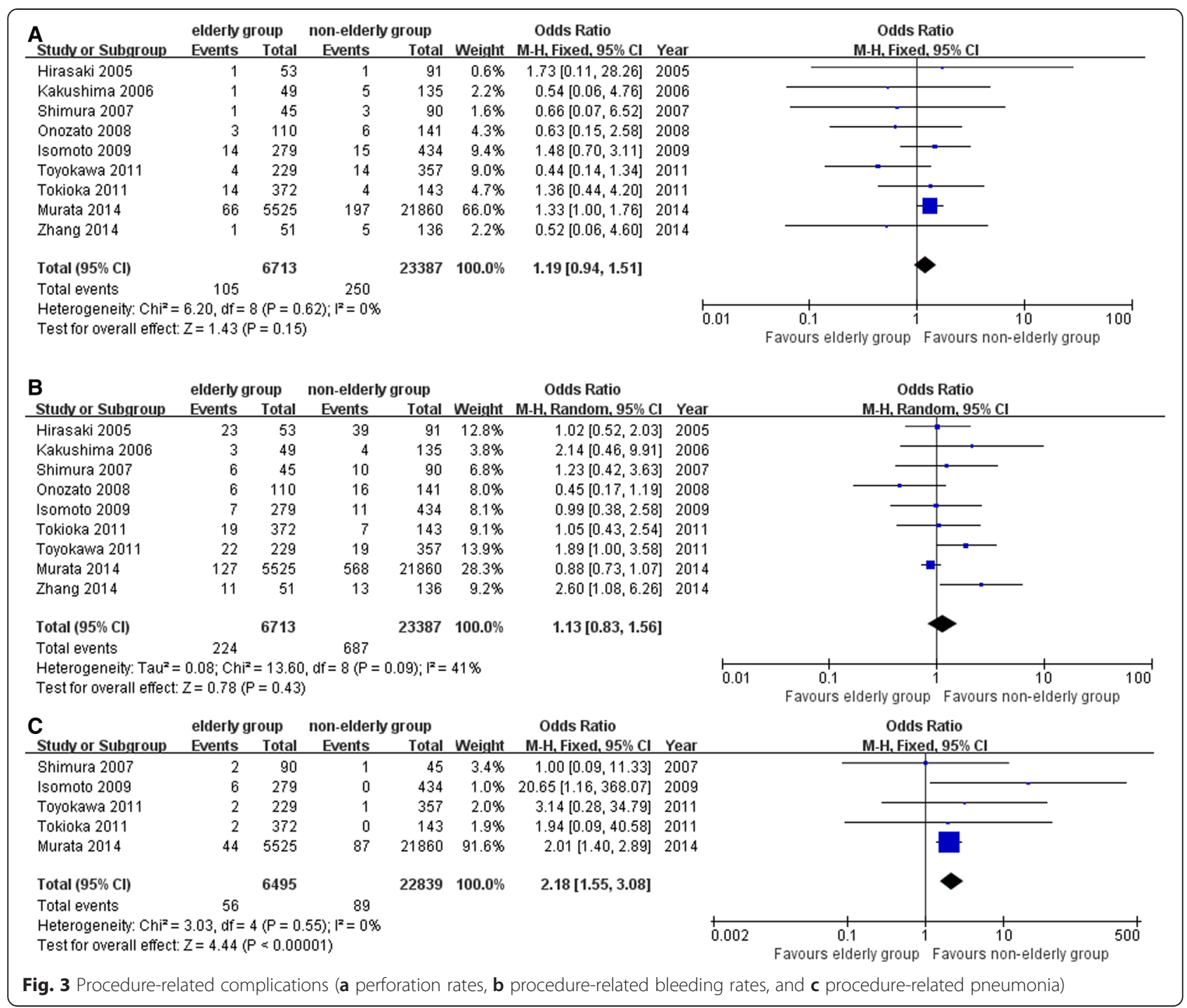

Table 2 Summary of operative outcomes and procedure-related complications

\begin{tabular}{|c|c|c|c|c|c|c|c|c|c|c|c|c|c|c|}
\hline \multirow[t]{3}{*}{ Study } & \multicolumn{2}{|l|}{ PT } & \multicolumn{2}{|c|}{ EBR (\%) } & \multicolumn{2}{|c|}{ HCR (\%) } & \multicolumn{8}{|c|}{ Procedure-related complications } \\
\hline & \multirow[t]{2}{*}{$\mathrm{E}$} & \multirow[t]{2}{*}{ NE } & \multirow[t]{2}{*}{ E } & \multirow[t]{2}{*}{$\mathrm{NE}$} & \multirow[t]{2}{*}{$\mathrm{E}$} & \multirow[t]{2}{*}{$\mathrm{NE}$} & \multicolumn{4}{|l|}{$E$} & \multicolumn{4}{|l|}{ NE } \\
\hline & & & & & & & $\mathrm{TL}$ & Perforation & Bleeding & Pneumonia & $\mathrm{TL}$ & Perforation & Bleeding & Pneumonia \\
\hline Hirasaki [13] & 67 & 77 & 96 & 92 & 81 & 82 & 53 & 1 & 23 & NR & 91 & 1 & 39 & NR \\
\hline Shimura [14] & 110 & NR & 81.1 & 86.7 & NR & NR & 45 & 1 & 2 & 2 & 90 & 3 & 4 & 1 \\
\hline Kakushima [15] & NR & NR & NR & NR & NR & NR & 49 & 1 & 3 & 0 & 135 & 5 & 4 & 0 \\
\hline Onozato [16] & NR & NR & NR & NR & NR & NR & 110 & 3 & 6 & NR & 141 & 6 & 16 & NR \\
\hline Isomoto [17] & NR & $N R$ & 93.9 & 97.9 & 91.5 & 94.5 & 269 & 7 & 14 & 6 & 434 & 11 & 15 & 0 \\
\hline Toyokawa [18] & 123 & 119 & 92 & 90 & 80 & 82 & 229 & 4 & 22 & 2 & 357 & 14 & 19 & 1 \\
\hline Tokioka [19] & 64 & 77 & NR & NR & NR & NR & 372 & 14 & 19 & 2 & 143 & 4 & 7 & 0 \\
\hline Murata [20] & NR & NR & 97.3 & 95.8 & 98.1 & 97.9 & 5525 & 66 & 127 & 44 & 21,860 & 197 & 568 & 87 \\
\hline Zhang [21] & 67.3 & 37.9 & 98 & 97.1 & 94.1 & 96.3 & 51 & 1 & 11 & NR & 136 & 5 & 13 & NR \\
\hline
\end{tabular}




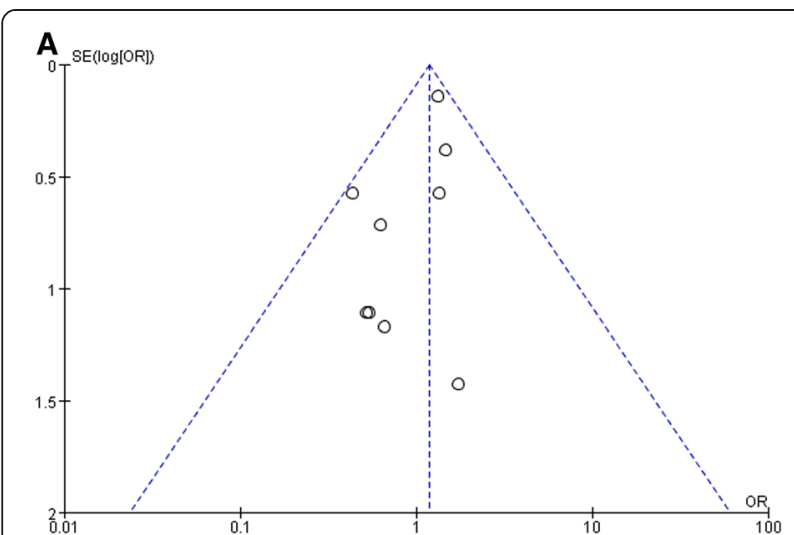

B
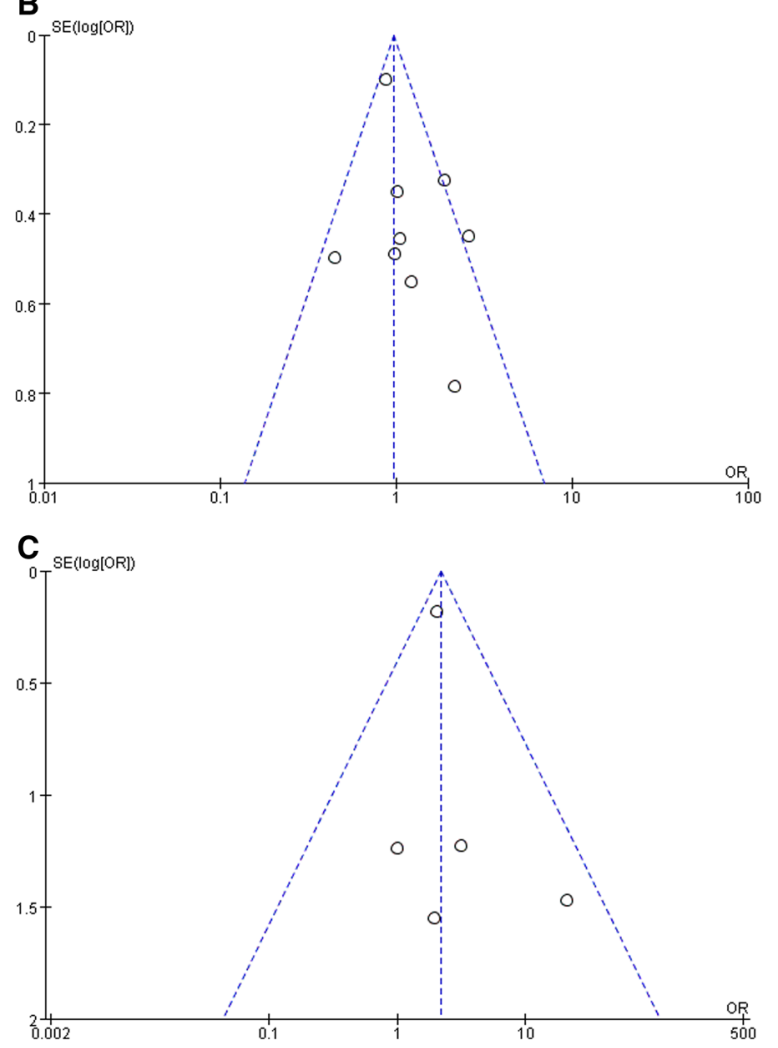

Fig. 4 Funnel plots based on the procedure-related complications (a perforation, b procedure-related bleeding, and c procedure-related pneumonia)

\section{Conclusions}

In conclusion, ESD is an effective and safe procedure for elderly patients with EGC, but attentive care should be carried out to avoid procedure-related pneumonia. More well-designed large scale clinical studies are awaited and further evaluation of the utility of ESD elderly patients with EGC should be conducted to confirm our findings.

\section{Competing interests}

The authors declare they have no competing interests.

\section{Authors' contributions}

JPL wrote the manuscript. JPL and YPZ collected literatures and data. JPL, YPZ, and MX conducted the analysis of pooled data. JMS and SJC proofread and revised the manuscript. All authors read and approved the final manuscript.

\section{Acknowledgements}

This work was supported by the National Natural Science Foundation of China (81302070, 81372623), Zhejiang province key science and technology innovation team (2013TD13). We thank Dr. Takaya Shimura for his kind helps and Dr. Yu Pan for his constructive suggestions.

\section{Author details}

'Department of Gastroenterology, Sir Run Run Shaw Hospital, School of Medicine, Zhejiang University, 3 East Qingchun Road, Hangzhou 310016, Zhejiang, People's Republic of China. ${ }^{2}$ Institute of Gastroenterology, Zhejiang University, 3 East Qingchun Road, Hangzhou 310016, Zhejiang, People's Republic of China. ${ }^{3}$ Jiangsu Province Key Laboratory of Anesthesiology, Xuzhou Medical College, Xuzhou, People's Republic of China. ${ }^{4}$ Jiangsu Province Key Laboratory of Anesthesia and Analgesia Application Technology, Xuzhou, Peoples' Republic of China.

Received: 18 April 2015 Accepted: 22 September 2015

Published online: 06 October 2015

\section{Reference}

1. Goh LY, Leow AH, Goh KL. Observations on the epidemiology of gastrointestinal and liver cancers in the Asia-Pacific region. J Dig Dis. 2014;15:463-8.

2. Fock KM. Review article: the epidemiology and prevention of gastric cancer. Aliment Pharmacol Ther. 2014;40:250-60.

3. Japanese Gastric Cancer Association: Japanese classification of gastric carcinoma: 3rd English edition. Gastric Cancer. 2011:14:101-112.

4. Nakamoto S, Sakai Y, Kasanuki J, Kondo F, Ooka Y, Kato K, et al. Indications for the use of endoscopic mucosal resection for early gastric cancer in Japan: a comparative study with endoscopic submucosal dissection. Endoscopy. 2009:41:746-50

5. Oka S, Tanaka S, Higashiyama M, Numata N, Sanomura Y, Yoshida S, et al. Clinical validity of the expanded criteria for endoscopic resection of undifferentiated-type early gastric cancer based on long-term outcomes. Surg Endosc. 2014;28:639-47.

6. Watanabe K, Ogata S, Kawazoe S, Watanabe K, Koyama T, Kajiwara T, et al. Clinical outcomes of EMR for gastric tumors: historical pilot evaluation between endoscopic submucosal dissection and conventional mucosal resection. Gastrointest Endosc. 2006;63:776-82.

7. Li H, Han X, Su L, Zhu W, Xu W, Li K, et al. Laparoscopic radical gastrectomy versus traditional open surgery in elderly patients with gastric cancer: Benefits and complications. Mol Clin Oncol. 2014;2:530-4.

8. Lim CH, Kim SW, Kim WC, Kim JS, Cho YK, Park JM, et al. Anemia after gastrectomy for early gastric cancer: long-term follow-up observational study. World J Gastroenterology. 2012;18:6114-9.

9. Hu Y, Kim HI, Hyung WJ, Song KJ, Lee JH, Kim YM, et al. Vitamin B(12) deficiency after gastrectomy for gastric cancer: an analysis of clinical patterns and risk factors. Ann Surg. 2013;258:970-5.

10. Higgins JP, Thompson SG, Deeks JJ, Altman DG. Measuring inconsistency in meta-analyses. BMJ (Clinical research ed). 2003;327:557-60.

11. Robins J, Breslow N, Greenland S. Estimators of the Mantel-Haenszel variance consistent in both sparse data and large-strata limiting models. Biometrics. 1986;42:311-23.

12. SanGiovanni JP, Berkey CS, Dwyer JT, Colditz GA. Dietary essential fatty acids, long-chain polyunsaturated fatty acids, and visual resolution acuity in healthy fullterm infants: a systematic review. Early Hum Dev. 2000;57:165-88.

13. Hirasaki S, Tanimizu M, Nasu J, Shinji T, Koide N. Treatment of elderly patients with early gastric cancer by endoscopic submucosal dissection using an insulated-tip diathermic knife. Int Med (Tokyo, Japan). 2005:44:1033-8.

14. Shimura T, Joh T, Sasaki M, Kataoka H, Tanida S, Ogasawara N, et al. Endoscopic submucosal dissection is useful and safe for intramucosal gastric neoplasms in the elderly. Acta gastro-enterologica Belgica. 2007;70:323-30. 
15. Kakushima N, Fujishiro M, Kodashima S, Muraki Y, Tateishi A, Yahagi N, et al. Technical feasibility of endoscopic submucosal dissection for gastric neoplasms in the elderly Japanese population. J Gastroenterol Hepatol. 2007;22:311-4.

16. Onozato $Y$, Kakizaki S, Ishihara H, lizuka H, Sohara N, Okamura S, et al. Feasibility of endoscopic submucosal dissection for elderly patients with early gastric cancers and adenomas. Dig Endosc. 2008;20:12-6.

17. Isomoto H, Ohnita K, Yamaguchi N, Fukuda E, Ikeda K, Nishiyama H, et al. Clinical outcomes of endoscopic submucosal dissection in elderly patients with early gastric cancer. Euro J Gastroenterol Hepatol. 2010;22:311-7.

18. Toyokawa T, Fujita I, Morikawa T, Okamoto A, Miyasaka R, Watanabe K, et al. Clinical outcomes of ESD for early gastric neoplasms in elderly patients. Eur J Clin Investig. 2011;41:474-8.

19. Tokioka S, Umegaki E, Murano M, Takeuchi N, Takeuchi T, Kawakami K, et al. Utility and problems of endoscopic submucosal dissection for early gastric cancer in elderly patients. J Gastroenterol Hepatol. 2012;27 Suppl 3:63-9.

20. Murata A, Muramatsu K, Ichimiya Y, Kubo T, Fujino Y, Matsuda S. Endoscopic submucosal dissection for gastric cancer in elderly Japanese patients: an observational study of financial costs of treatment based on a national administrative database. J Dig Dis. 2014;15:62-70.

21. Zhang Y, Huang L, Li L, Ji F. Endoscopic submucosal dissection for early gastric neoplasms in elderly patients. J Laparoendoscopic Advanced Sur Tech A. 2014;24:391-8.

22. World Health Organization. World Health Statistics 2012. Available from URL: http://www.who.int/gho/publications/world_health_statistics/ EN WHS2012 Full.pdf.

23. Yancik $R$, Ries $L A$. Cancer in older persons: an international issue in an aging world. Semin Oncol. 2004;31:128-36.

24. Shin A, Kim J, Park S. Gastric cancer epidemiology in Korea. J Gastric cancer. 2011;11:135-40

25. Japanese Gastric Cancer Association: Japanese gastric cancer treatment guidelines 2010 (ver. 3). Gastric Cancer. 2011;14:113-123.

26. Chung IK, Lee JH, Lee SH, Kim SJ, Cho JY, Cho WY, et al. Therapeutic outcomes in 1000 cases of endoscopic submucosal dissection for early gastric neoplasms: Korean ESD Study Group multicenter study. Gastrointest Endosc. 2009;69:1228-35

27. Tanabe S, Ishido K, Higuchi K, Sasaki T, Katada C, Azuma M, et al. Long-term outcomes of endoscopic submucosal dissection for early gastric cancer: a retrospective comparison with conventional endoscopic resection in a single center. Gastric Cancer. 2014;17:130-6.

28. Min BH, Lee JH, Kim JJ, Shim SG, Chang DK, Kim YH, et al. Clinical outcomes of endoscopic submucosal dissection (ESD) for treating early gastric cancer: comparison with endoscopic mucosal resection after circumferential precutting (EMR-P). Dig Liver Dis. 2009;41:201-9.

29. Park YM, Cho E, Kang HY, Kim JM. The effectiveness and safety of endoscopic submucosal dissection compared with endoscopic mucosal resection for early gastric cancer: a systematic review and metaanalysis. Surg Endosc. 2011:25:2666-77.

30. Facciorusso A, Antonino M, Di Maso M, Muscatiello N. Endoscopic submucosal dissection vs endoscopic mucosal resection for early gastric cancer: A meta-analysis. World J gastrointestinal endoscopy. 2014;6:555-63.

31. Oka S, Tanaka S, Kaneko I, Mouri R, Hirata M, Kawamura T, et al. Advantage of endoscopic submucosal dissection compared with EMR for early gastric cancer. Gastrointest Endosc. 2006;64:877-83.

32. Ahn JY, Choi KD, Choi JY, Kim MY, Lee JH, Choi KS, et al. Procedure time of endoscopic submucosal dissection according to the size and location of early gastric cancers: analysis of 916 dissections performed by 4 experts. Gastrointest Endosc. 2011;73:911-6.

33. Abe S, Oda I, Suzuki H, Nonaka S, Yoshinaga S, Odagaki T, et al. Short- and long-term outcomes of endoscopic submucosal dissection for undifferentiated early gastric cancer. Endoscopy. 2013:45:703-7.

34. Isomoto H, Shikuwa S, Yamaguchi N, Fukuda E, Ikeda K, Nishiyama H, et al. Endoscopic submucosal dissection for early gastric cancer: a large-scale feasibility study. Gut. 2009;58:331-6.

35. Kim M, Jeon SW, Cho KB, Park KS, Kim ES, Park CK, et al. Predictive risk factors of perforation in gastric endoscopic submucosal dissection for early gastric cancer: a large, multicenter study. Surg Endosc. 2013;27:1372-8.

36. Ohta T, Ishihara R, Uedo N, Takeuchi Y, Nagai K, Matsui F, et al. Factors predicting perforation during endoscopic submucosal dissection for gastric cancer. Gastrointest Endosc. 2012;75:1159-65.
37. Tsuji Y, Ohata K, Ito T, Chiba H, Ohya T, Gunji T, et al. Risk factors for bleeding after endoscopic submucosal dissection for gastric lesions. World J Gastroenterology. 2010;16:2913-7

38. Miyahara K, Iwakiri R, Shimoda R, Sakata Y, Fujise T, Shiraishi R, et al. Perforation and postoperative bleeding of endoscopic submucosal dissection in gastric tumors: analysis of 1190 lesions in low- and high-volume centers in Saga, Japan. Digestion. 2012;86:273-80.

39. Lim JH, Kim SG, Kim JW, Choi YJ, Kwon J, Kim JY, et al. Do antiplatelets increase the risk of bleeding after endoscopic submucosal dissection of gastric neoplasms? Gastrointest Endosc. 2012;75:719-27.

40. Sanomura Y, Oka S, Tanaka S, Numata N, Higashiyama M, Kanao H, et al. Continued use of low-dose aspirin does not increase the risk of bleeding during or after endoscopic submucosal dissection for early gastric cancer. Gastric Cancer. 2014;17:489-96.

41. Park CH, Kim H, Kang YA, Cho IR, Kim B, Heo SJ, et al. Risk factors and prognosis of pulmonary complications after endoscopic submucosal dissection for gastric neoplasia. Dig Dis Sci. 2013:58:540-6.

42. Akasaka T, Nishida T, Tsutsui S, Michida T, Yamada T, Ogiyama H, et al. Short-term outcomes of endoscopic submucosal dissection (ESD) for early gastric neoplasm: multicenter survey by osaka university ESD study group. Dig Endosc. 2011;23:73-7.

43. Gong EJ, Kim Do H, Jung HY, Lim H, Ahn JY, Choi KS, et al. Pneumonia after endoscopic resection for gastric neoplasm. Dig Dis Sci. 2014;59:2742-8.

44. Oda I, Suzuki H, Nonaka S, Yoshinaga S. Complications of gastric endoscopic submucosal dissection. Dig Endosc. 2013;25 Suppl 1:71-8.

45. Kusano C, Iwasaki M, Kaltenbach T, Conlin A, Oda I, Gotoda T. Should elderly patients undergo additional surgery after non-curative endoscopic resection for early gastric cancer? Long-term comparative outcomes. Am J Gastroenterol. 2011;106:1064-9.

46. Nakamura K, Honda K, Akahoshi K, Ihara E, Matsuzaka H, Sumida Y, et al. Suitability of the expanded indication criteria for the treatment of early gastric cancer by endoscopic submucosal dissection: Japanese multicenter large-scale retrospective analysis of short- and long-term outcomes. Scand J Gastroenterol. 2015;50(4):413

47. Choi MK, Kim GH, Park Do Y, Song GA, Kim DU, Ryu DY, et al. Long-term outcomes of endoscopic submucosal dissection for early gastric cancer: a single-center experience. Surg Endosc. 2013;27:4250-8.

48. Pimentel-Nunes $P$, Mourao F, Veloso N, Afonso LP, Jacome M, Moreira-Dias $L$, et al. Long-term follow-up after endoscopic resection of gastric superficial neoplastic lesions in Portugal. Endoscopy. 2014;46:933-40.

\section{Submit your next manuscript to BioMed Central and take full advantage of:}

- Convenient online submission

- Thorough peer review

- No space constraints or color figure charges

- Immediate publication on acceptance

- Inclusion in PubMed, CAS, Scopus and Google Scholar

- Research which is freely available for redistribution

Submit your manuscript at www.biomedcentral.com/submit
C Biomed Central 